\title{
Occurrence of Polychlorinated Biphenyls (PCBs) on Suspended Sediment in the Donna Canal, Hidalgo County, Texas, 1999-2001
}

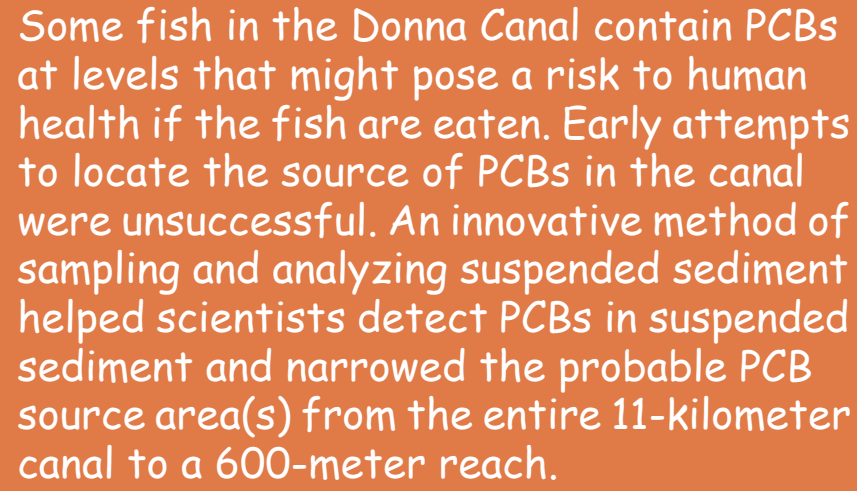

The Donna Canal is a popular fishing spot for residents of Hidalgo County. The 11.3-kilometer-long irrigation canal and water-supply system is home to some of the best bass and catfish angling in the Rio Grande Valley of South Texas, and fish from the Donna Canal often end up on dinner tables. The fish, however, might be contaminated with PCBs, a group of toxic and carcinogenic (cancer-causing) compounds. PCBs are hydrophobic (meaning "water fearing"). These kinds of chemicals do not dissolve in water but instead adsorb to sediment and become incorporated into animal tissue. Small animals living in or around sediment contaminated with PCBs accumulate these toxic chemicals in their bodies. These creatures are eaten by other animals, which concentrate the PCBs in their tissue, and in this way, PCBs work their way up the food chain. Often the final consumers and concentrators of PCBs are humans.

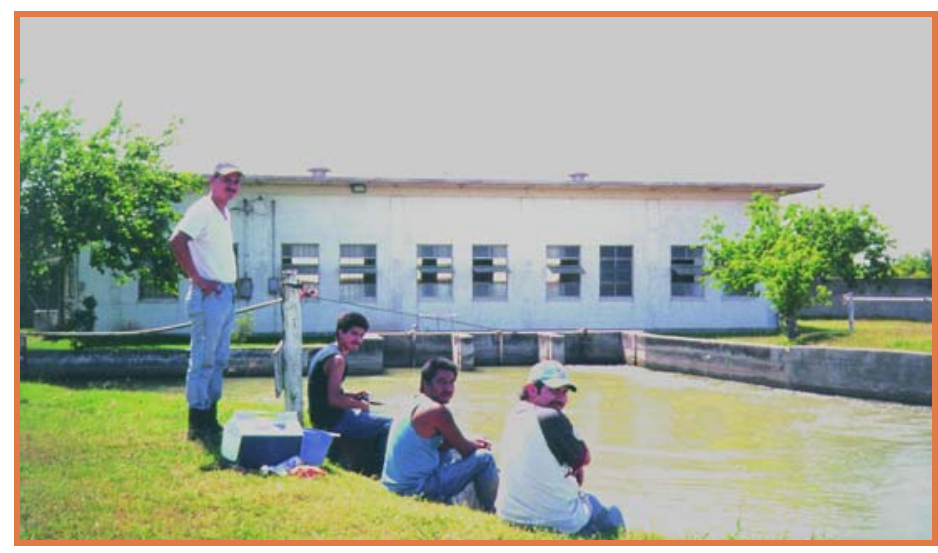

Local fishermen at the Donna Canal pumphouse.

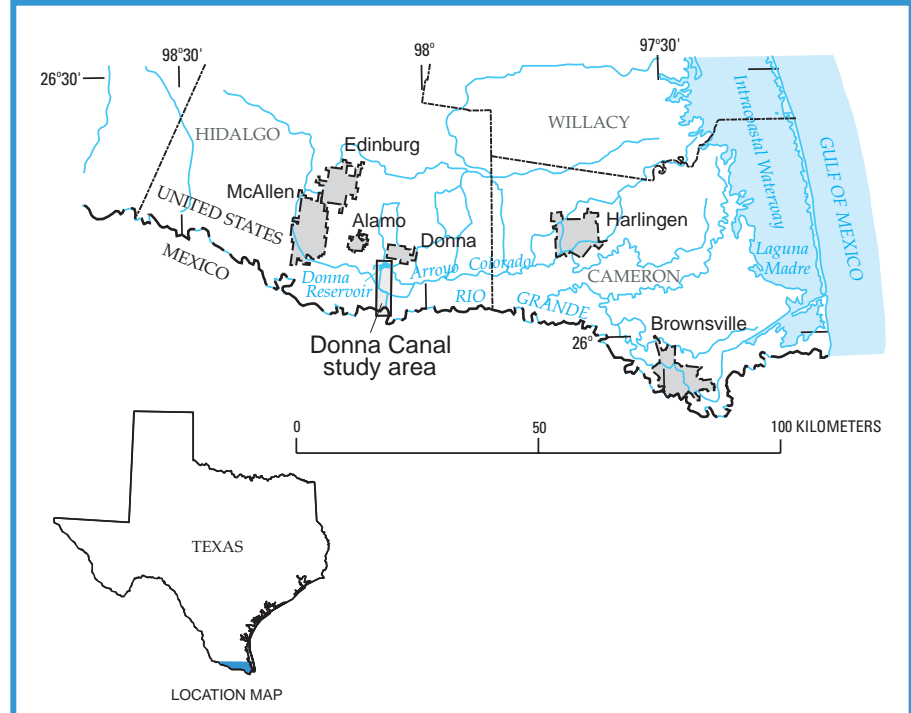

Figure 1. Location of the Donna Canal study area.

Water is pumped from the Rio Grande into the Donna Canal at an average rate of about 3.4 cubic meters per second. The Donna Canal carries the water north by simple gravity flow. The water from the canal is used for irrigation of nearby farmland. On its way north, the canal carries the water underneath a perennial stream, the Arroyo Colorado, by way of an underground siphon. The Donna Canal ultimately flows into Donna Reservoir, which supplies drinking water to the nearby municipalities of Donna and Alamo.

PCBs in the Donna Canal were first detected in 1993 by the U.S. Environmental Protection Agency (USEPA) during an environmental study of the Lower Rio Grande Valley. As part of the study, the USEPA tested samples of cooked fish from nine representative households, as well as samples of blood and urine from the individuals who consumed the fish. One carp fillet from a fish reportedly caught in the Donna Canal had a PCB concentration of 399 milligrams per kilogram, more than 1,500 times higher than the concentration thought to pose a health risk to an adult (U.S. Environmental Protection Agency, 1994). The individuals who consumed the fish had elevated levels of PCBs in their blood.

During 1994-2000, the Texas Department of Health (TDH) and the Texas Natural Resource Conservation Commission (TNRCC) sampled more fish and found many with elevated concentrations of PCBs, although none were as high as those in 
the first fish analyzed in 1993 by the USEPA. The risk of cancer was calculated to be 1 in 174 for adults consuming two 8-ounce meals per week of fish caught from the Donna Canal (Buchanan, 1997). Possession of fish from the Donna Canal was banned while the TDH and the TNRCC tried to find the source of the PCBs.

During 1994-97, more than 75 samples of water and bed sediment from the canal, the reservoir, surrounding reservoirs, the Rio Grande, public water supplies, and a ground-water monitoring well were analyzed. The only PCB detection was in a sample from a drainage ditch 0.3 kilometer from the canal (Webster and others, 1998).

In 1997, the TNRCC asked the U.S. Geological Survey (USGS) for assistance in detecting the source of the PCBs. This report summarizes the results of the USGS investigation.

\section{Sampling of Suspended Sediment}

Water in the Donna Canal is pumped directly from the Rio Grande and flows north about 11 kilometers to Donna Reservoir. The pumping rate is set at the beginning of each day. On the days samples were collected, the pumping rate ranged from 1,420 to 4,530 liters per second, and the flow rate ranged from about 0.07 to 0.14 meter per second. The water in the canal looks cloudy or murky because the constant flow of water keeps sediment in suspension in the water. Some of the suspended sediment is pumped into the canal from the Rio Grande, and some of the sediment comes from erosion of the sides of the canal.

To try to find the source of the PCBs, the USGS used a different type of sampling approach-collection and analysis of the suspended sediment. Because PCBs do not

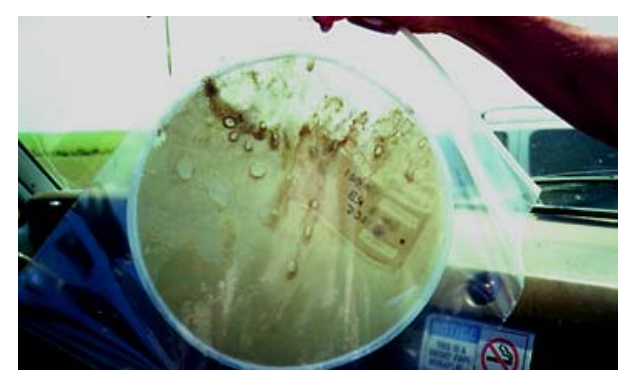

Suspended sediment from Donna Canal collected on a filter.

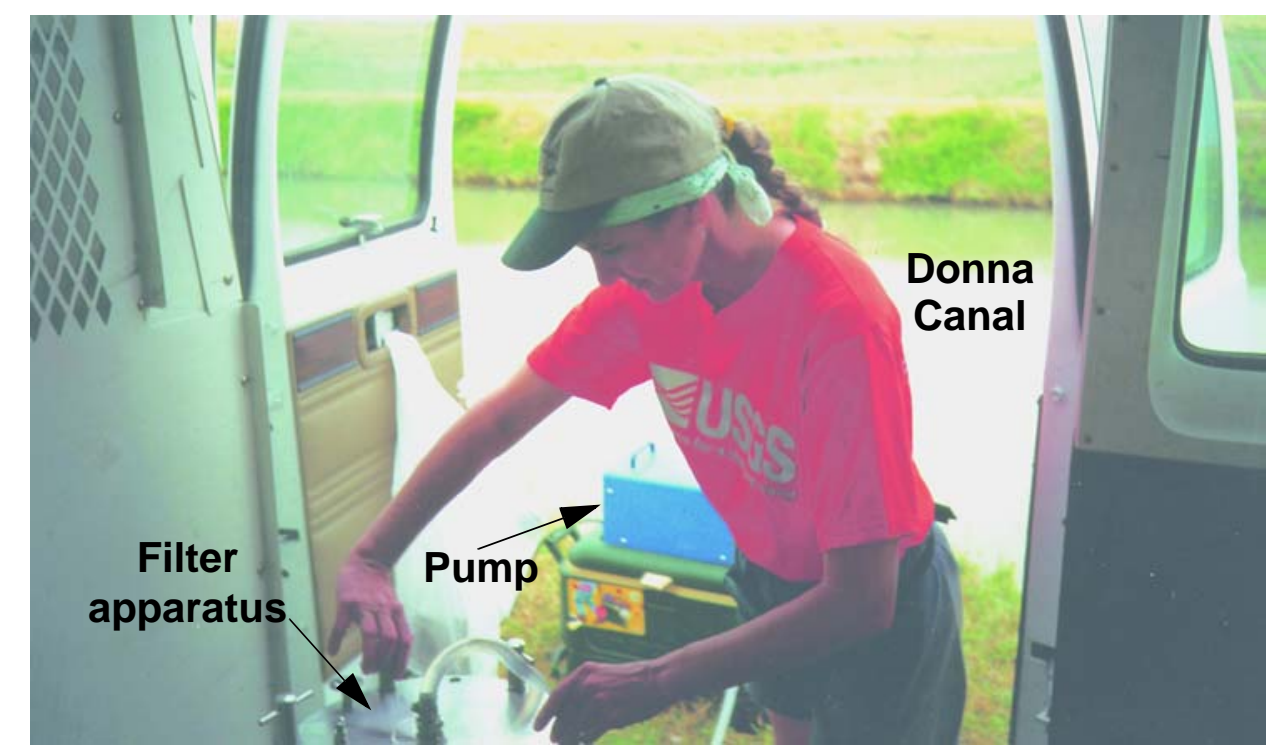

Collecting a suspended sediment sample from the Donna Canal. dissolve readily in water but instead stick to sediment, they usually are not detected in water samples, even in contaminated environments. By removing the suspended sediment from the water and analyzing it directly, the PCBs are more likely to be detected. In other words, the USGS approach was to look for the PCBs where they were expected to be.
Suspended sediment was collected for analysis by filtering. At each sampling site, tubing was suspended in the canal about 2.5 meters from the bank at a depth of about 1 meter, and water was pumped from the canal with a peristaltic pump; at bridges and at the mouth of a siphon in the canal, the tubing was suspended in the center of the canal. For all but the final round

\section{- What are PCBs?}

PCBs are synthetic compounds that were used in the United States in the 1950s to 1970s for many industrial purposes. They were used mostly as coolants and lubricants in transformers, capacitors, and other electrical equipment. PCBs also were used as plasticizers in paints, plastics, and rubber products; in pigments, dyes, and carbonless copy paper; and in many other products (U.S. Environmental Protection Agency, 2001). Because of the threat they pose to human health, the U.S. Government banned PCB production and use in 1976. PCBs break down to other, lessharmful compounds extremely slowly, and PCBs that were released to the environment decades ago are still a threat to human health today. The fate of many PCBs used before the ban is largely unknown. PCBs have been found in a variety of residential and industrial locations and dumpsites throughout the United States and Canada. Some PCBs were illegally dumped or buried after their use was banned. The exact location of the PCB source contaminating the Donna Canal is unknown, but the effect of these chemicals on the local environment is seen in contaminated fish in the Donna Canal.

\section{- How does eating PCB-contaminated fish affect humans?}

PCBs concentrate in the skin and fatty tissue of human consumers and most animals and can affect the skin, liver, stomach, and thyroid gland. It also can affect the nervous system causing severe degenerative conditions. Other effects of PCBs in animals include changes in the immune system, behavioral alterations, and impaired reproduction. PCBs are not known to cause birth defects. Rats that ate food containing high levels of PCBs for 2 years developed liver cancer. The EPA and the International Agency for Research on Cancer have determined that PCBs are probably carcinogenic to humans. Studies have shown that babies born to women who ate PCB-contaminated fish have shown abnormal responses in tests of infant behavior (Agency for Toxic Substances and Disease Registry, 2001). 


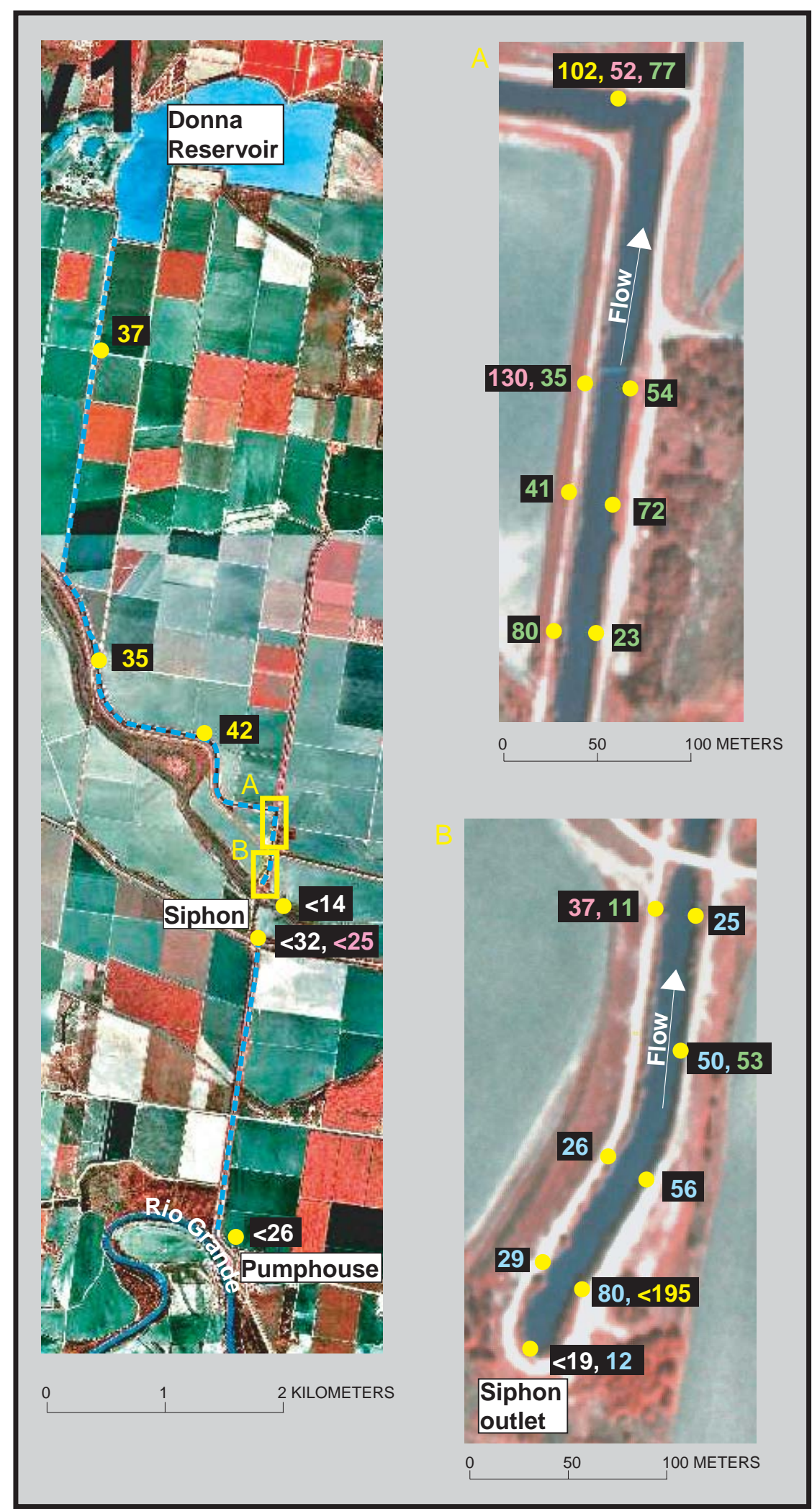

Figure 2. Aerial photographs of the Donna Canal (indicated by the dashed blue line), sampling sites, and concentrations detected. Flow is to the north from the pumphouse toward the reservoir. To the right are enlarged images of two areas of the canal chosen for more closely spaced sampling. Sampling sites are indicated with yellow dots, and results of samples collected during the same sampling trip are shown in the same color: white (February 1999), yellow (July 1999), pink (January 2000), blue (July 2000), and green (April 2001). All concentrations are in micrograms per kilogram of sediment collected. of sampling, water was pumped through a 298millimeter-diameter glass fiber filter with a nominal pore size of 0.5 micrometer. For the final round of sampling, water was pumped through similarly sized PTFE (Teflon) filters. Water was pumped through the filter until the filter clogged; three filters were used at each site, and a total of 25 to 140 liters of water was filtered. The filters were put inside a baked glass jar and chilled until sent to the laboratory for analysis. Unfiltered water samples also were submitted for analysis of total suspended sediment concentration. PCBs were analyzed by gas chromatography/mass spectrometry (GC/MS) following the method of Foreman and others (1995).

\section{Sampling Results and Conclusion}

Five separate sampling trips to the Donna Canal were made to collect suspended sediment. The overall strategy was to narrow the search for the PCB source area(s) from the entire 11-kilometer length to a much shorter distance by collecting samples at more closely spaced intervals. The sampling sites and spacing were chosen on the basis of the results from the previous event (fig. 2).

\section{Round 1: February 1999}

- No PCBs were detected during the first round of sampling when samples were collected from sites near the pumphouse, at the siphon inlet, at the siphon outlet, and in the Arroyo Colorado (results shown in white, fig. 2). These results suggested that the source of the PCBs must be downstream (north) of the siphon outlet.

\section{Round 2: July 1999}

D The results of the second sampling round (shown in yellow, fig. 2) confirmed that the source was in or downstream of the siphon outlet, and that it was probably upstream (south) of the 90-degree bend. On the basis of these detections, samples were collected at more closely spaced intervals in the reach downstream of the siphon to try to pinpoint the PCB source.

\section{Round 3: January 2000}

- The results of the third sampling round (shown in pink, fig. 2) indicated a possible PCB source in the 200-meter reach downstream of the siphon outlet and a possible second source at least 150 meters upstream of the 90-degree bend.

\section{Round 4: July 2000}

On the basis of previous results, the fourth sampling round samples were collected at about 50-meter intervals on both banks of the canal downstream of the siphon outlet. The results (shown in blue, fig. 2) indicated a potential PCB source on the right bank of the canal, just downstream of the siphon outlet.

\section{Round 5: April 2001}

In an attempt to pinpoint the location of an additional source or sources upstream of the 90-degree bend, the fifth sampling-round samples were collected 
at about 50-meter intervals in the reach upstream of the 90-degree bend. The results (shown in green, fig. 2) confirmed the presence of PCBs in suspended sediment along this section of the canal but do not identify any one location as a probable PCB source. One or several sources of PCBs might be present along this stretch of the canal.

The TNRCC also participated in the fifth and final sampling round, collecting whole water and bed sediment at selected locations in the canal and extracting two soil borings from the area of the canal just downstream of the siphon outlet. However, no PCBs were detected in the TNRCC water or sediment samples, and this additional sampling was unsuccessful in further pinpointing the location of the PCB source(s).

In conclusion, the source or sources of the PCBs must be located between the siphon outlet and the 90-degree bend in the Donna Canal.

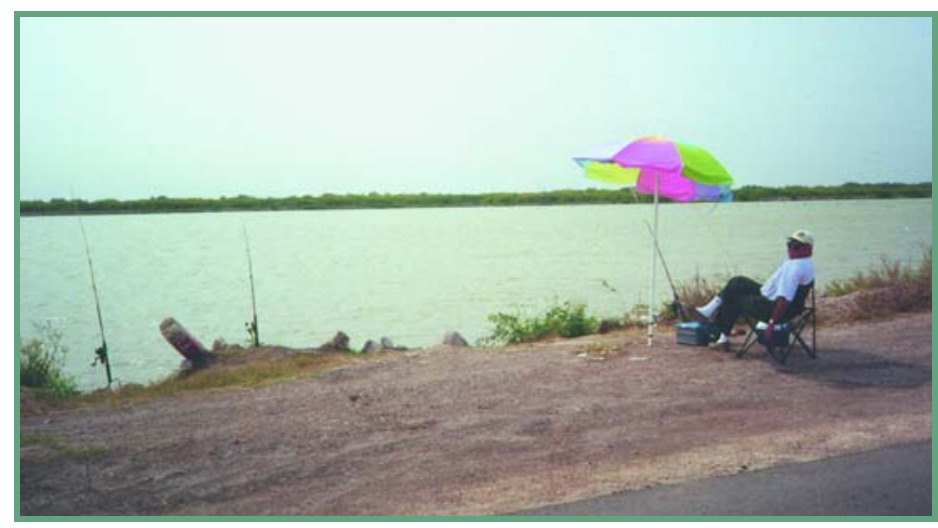

Fisherman at Donna Reservoir, Hidalgo County.

\section{What is the future of the Donna Canal?}

Using the information gathered from the suspended sediment sampling during 1999-2001, the TNRCC has begun a multiphase project to investigate and remediate all sources of PCBs in the Donna Canal. Efforts will be concentrated in the 600-meter reach identified by the USGS as the most likely reach of the canal to contain the source(s) of the PCB contamination. The first phase of the TNRCC project began in August 2001 and involves additional assessment and delineation of the PCB source. Subsequent phases of the project will involve the development of a remediation plan and implementation of remedial actions in the canal.

\section{References}

Agency for Toxic Substances and Disease Registry, 2001,

ToxFAQ for polychlorinated biphenyls (PCBs): Accessed

August 24, 2001, at URL

http://www.atsdr.cdc.gov/tfacts 17.html

Buchanan, T.A., 1997, Polychlorinated biphenyls in fish in the

Donna Reservoir and Canal system and in the Lower Rio

Grande Valley of Texas: Houston, University of Texas Health Science Center, Masters thesis, 84 p.

Foreman, W.T., Connor, B.G., Furlong, E.T., Vaught, D.G., and Merten, L.M., 1995, Methods of analysis by the U.S. Geological Survey National Water Quality LaboratoryDetermination of organochlorine pesticides and polychlorinated biphenyls in bottom sediment by dual

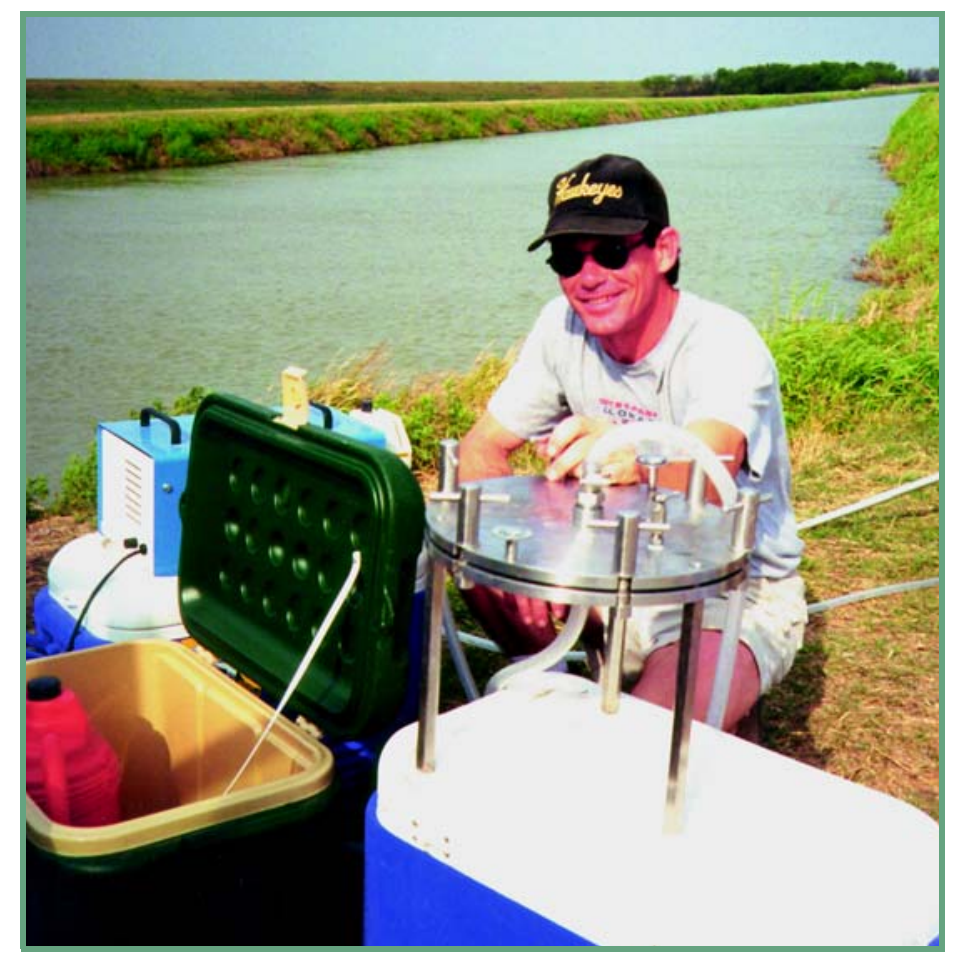

Sampling suspended sediment at Donna Canal.

capillary-column gas chromatography with electroncapture detection: U.S. Geological Survey Open-File Report 94-140, 78 p.

U.S. Environmental Protection Agency, 1994, Lower Rio Grande Valley environmental monitoring study-Report to the community in the pilot project: Washington, D.C., 20 p.

2001, PCBs, polychlorinated biphenyls: Accessed August 24, 2001, at URL

http://www.epa.gov/Region8/toxics_poisons/pcb/pcb.html

Webster, C.F., Buchanan, T.A., Kirkpatrick, J., and Miranda, R.M., 1998, Polychlorinated biphenyls in Donna Reservoir and contiguous waters: Texas Natural Resource Conservation Commission, Agency Studies AS-161, 46 p.

- B.J. Mahler, P.C. Van Metre, and R.M. Miranda

Photographs by B.J. Mahler and M.P. Cordell

Any use of trade, product, or firm names is for descriptive purposes only and does not imply endorsement by the U.S. Government.

\section{Information on technical reports and hydrologic data related to this study can be obtained from:}

District Chief

U.S. Geological Survey

8027 Exchange Dr.

Austin, TX 78754-4733

E-mail: dc_tx@usgs.gov
Phone: (512) 927-3500

FAX: (512) 927-3590

World Wide Web:

http://tx.usgs.gov/ 